\title{
A Rare Case Report of Small Bowel Perforation Associated with Cryptorchidism in an Adult
}

\author{
Aman Singhal ${ }^{1}$, Nikita Jain ${ }^{2}$, Sneh S Shah ${ }^{3}$, Vijoy Singh ${ }^{4}$, Chandra Raychaudhuri ${ }^{5}$ \\ ${ }^{1}$ Assistant Professor, Department of Gen. Surgery, ${ }^{2}$ Junior Resident 3rd year, Department of Radiology, ${ }^{3}$ Junior Resident 2nd \\ year, Department of Gen. Surgery, ${ }^{4} \mathrm{HOD}$, Department of Gen. Surgery, ${ }^{5} \mathrm{HOD}$, Department of Radiology, Dhiraj Hospital, \\ Waghodia road, Piparia, Vadodara, Gujrat 390019, India
}

Corresponding author: Dr. Aman Singhal, Department of General Surgery, Dhiraj Hospital, Waghodia Road, Piparia, Vadodara, Gujrat 390019, India

DOI: http://dx.doi.org/10.21276/ijcmsr.2019.4.4.10

How to cite this article: Aman Singhal, Nikita Jain, Sneh S Shah, Vijoy Singh, Chandra Raychaudhuri. A Rare case report of small bowel perforation associated with cryptorchidism in an adult. International Journal of Contemporary Medicine Surgery and Radiology. 2019;4(4):D45-D46.

\section{A B S T R A C T}

Introduction: Small bowel obstruction is common complication after abdominal surgery, and can occur due to many reasons. Although obstruction leading to perforation of small bowel is less likely but can occur in some circumstances in which treatment was not taken or misdiagnosed.

Case report: We report here 25 year old male with small bowel obstruction caused by adhesions between right side undescended testis and terminal ileum leading to perforation of small bowel proximal to obstruction.

Conclusion: Cryptorchidism can cause Small bowel obstruction and perforation in patients with no history of abdominal surgery.

Keywords: Intestinal Obstruction and Perforation, Cryptorchidism, Adult

\section{INTRODUCTION}

Small bowel obstruction describes interruption of normal flow of intestinal contents in small bowel, and is common complication after abdominal surgery. Small bowel perforation can occur in patients who were not able to get proper treatment at proper time. It may result in unplanned hospital stay, additional costs and surgical intervention. ${ }^{1,2}$ Although post operative adhesions are mainly responsible for small bowel obstruction, other causes include malignancies or hernias. An undescended testis can be detected and surgically treated in a younger patient, and is not usually suspected as cause of Small bowel perforation in an adult because of its rarity. ${ }^{3,4}$ Herein, we report a rare case of small bowel perforation caused by bilateral cryptorchidism in an adult with no history of abdominal surgery.

\section{CASE REPORT}

A 25 year male patient presented to emergency department with complaints of abdominal pain, constipation, vomiting, and fever for the last 5 days. He got married when he was 20 year old and had 3 children; younger son was 8 months old. Patient had similar episodes of abdominal pain and constipation in the past at the age of 9 years and 13 years which were less severe and relieved by conservative management. Patient denied any history of abdominal surgery. On examination, Pulse- 142/min, BP- 100/60 mmHg, Temp$102^{\circ} \mathrm{F}, \mathrm{RR}-22 / \mathrm{min}$. Physical examination revealed sunken eyes and dry tongue. Abdomen was tense, tender, distended with guarding and rigidity. Scrotum was not well formed and testes were non palpable. Laboratory data were hemoglobin (9 gm\%) with leucocytosis (16500). Xray Abdoemen was done which showed diffuse dilatation of small bowel loops with multiple air fluid level and gas under diaphragm. USG shows free fluid in peritoneal cavity with internal echoes and absent peristalsis with bilateral testis absent in scrotal sac and ileo-inguinal region (Fig.1). CT showed perforation with mildly decreased enhancement of some ileal loops in lower abdomen with gas under diaphragm and multiple air fluid level. The patient was initially resuscitated and planned for surgery. On laparoscopic exploration, distended small bowel loops with fecal matter in peritoneal cavity were noted; fluid was aspirated and lavage was given; we tried to retract terminal ileum but were not able to do so, because of tension of uncertain origin. Small bowel was hugely dilated which hindered further laparoscopic view, so we took a decision to convert to open laparotomy. After conversion to open laparotomy we found that terminal ileum was rotated $180^{\circ}$ clockwise and an adherent right testis was noted $20 \mathrm{~cm}$ proximal from ileocaecal valve (Fig. 2). Proximal small bowel was dilated with a $2 \mathrm{~cm}$ perforation on anti-mesenteric border, $5 \mathrm{~cm}$ proximal to adhesion and the distal small bowel was collapsed. The right testicular vessels and vas deferens fixed the terminal ileum, acting like "adhesive bands" were ligated. Right orchidectomy was performed and small bowel continuity was preserved with resection anastomosis. Left testis was present in low abdominal position, seems to be normal macroscopically and was $3 * 2 * 1 \mathrm{~cm}$ in size. 


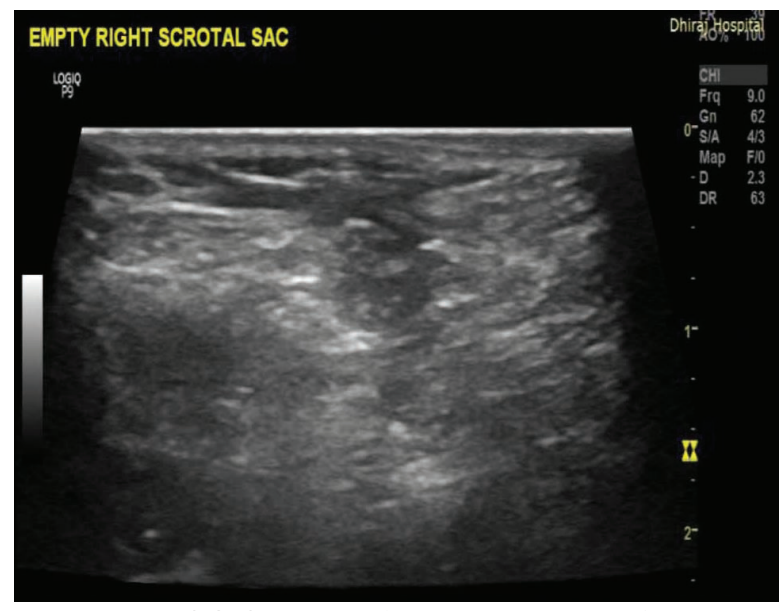

Figure-1: USG Scrotum shows empty scrotal sac.

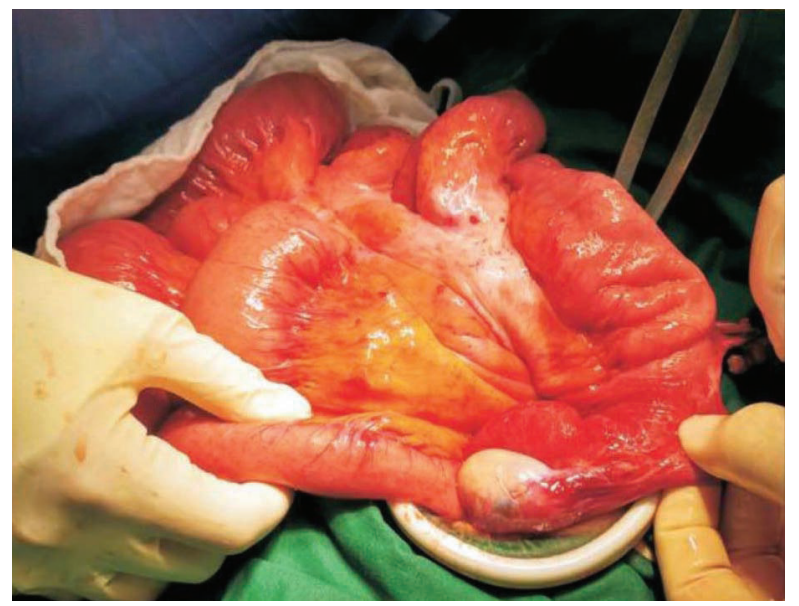

Figure-2: Terminal ileum adherent to right testis $20 \mathrm{~cm}$ proximal to ileocaecal valve

Left orchidopexy was done. The histopathology report was suggestive of atrophic testis $\left(5^{*} 4^{*} 2.5 \mathrm{~cm}\right)$ without malignancy. Post-operative period was uneventful and patient was discharged 12 days after surgery.

\section{DISCUSSION}

Cryptorchidism is usually diagnosed by clinical and radiological examination in the early life and treated by surgical intervention, with an incidence of $1-4 \%$ at the age of 1.45 Surgical intervention is required because of the possibility of trauma, infertility, torsion or malignancy. ${ }^{3,5,6}$ However cryptorchidism can be diagnosed in adults by clinical and radiological examination and the treatment of choice is orchidectomy. The patient in our case report had never complaint or care for any urinary, sexual, or fertility problems. Hence the diagnosis was delayed until symptoms developed.

The histopathology report revealed features of atrophic testis, including scattered nests of leydig cells hyperplasia with hyalinisation of seminiferous tubules without any spermatid. Malignant cells were not found in specimen.

Most common cause of small bowel obstruction is postoperative adhesions, so surgical history of abdomen is very important and should be considered first. If the patient has undergone abdominal surgery, the treated site, organ or previous surgical scar could provide clues to the location of transitional zone or adhesions. However if patient didn't have prior abdominal surgery so, other causes should be considered such as hernias, malignancies, and even strictures of small bowel due to IBD (inflammatory bowel disease).

Cryptorchidism is not a common cause of small bowel perforation although. This patient presented with symptoms caused by adhesion between an undescended, intra abdominal testis and the terminal ileum. There are many reports and studies about the causes, complications and treatment of cryptorchidism as well as the risk for infertility or malignancy. However, few reports have reported the correlation between cryptorchidism and an ileus or small bowel obstruction in children. ${ }^{7,8}$ To the best of our knowledge this is the first rare case report of small bowel perforation caused by bilateral cryptorchidism in an adult.

\section{CONCLUSION}

Among the causes of small bowel ileus, SAIO, intestinal obstruction and perforation in male patients without history of any previous abdominal surgery, surgeons should also consider cryptorchidism (extremely rare cause) as part of careful history and physical examination.

\section{REFERENCE}

1. Duron JJ, Silva NJ, du Montcel ST, Berger A, Muscari $\mathrm{F}$, Hennet $\mathrm{H}$, et al. Adhesive postoperative small bowel obstruction: incidence and risk factors of recurrence after surgical treatment: a multicenter prospective study. Ann Surg. 2006;244(1):750-757.

2. Oyasiji T, Angelo S, Kyriakides TC, Helton SW. Small bowel obstruction: outcome and cost implications of admitting service. Am Surg. 2010;76(5):687-691.

3. Rogers E, Teahan S, Gallagher H, Butler MR, Grainger $\mathrm{R}, \mathrm{McDermott} \mathrm{TE}$, et al. The role of orchiectomy in the management of postpubertal cryptorchidism. J Urol. 1998;159(2):851-854.

4. Radmayr C, Dogan HS, Hoebeke P, Kocvara R, Nijman $\mathrm{R}$, Stein R, et al. Management of undescended testes: European Association of Urology/European Society for Paediatric Urology Guidelines. J Pediatr Urol. 2016;12(6):335-343.

5. Kucheria R, Sahai A, Sami TA, Challacombe B, Godbole H, Khan MS, et al. Laparoscopic management of cryptorchidism in adults. Eur Urol.2005;48(3):453457.

6. van der Plas EM, van Brakel J, Meij-de Vries A, de Muinck Keizer-Schrama SM, Hazebroek FW, Hack WW, et al. Acquired undescended testes and fertility potential: is orchiopexy at diagnosis better than awaiting spontaneous descent? Andrology. 2015;3(5):677-684.

7. Dabek T, Heyda J. Cryptorchism as a cause of ileus. Wiad Lek.1973;26(1):1843-1844.

8. Fei X, Yang HR, Yu PF, Sheng HB, Gu GL. Idiopathic abdominal cocoon syndrome with unilateral abdominal cryptorchidism and greater omentum hypoplasia in a young case of small bowel obstruction. World J Gastroenterol. 2016;22(4):4958-4962.

\section{Source of Support: Nil; Conflict of Interest: None}

Submitted: 21-08-2019; Accepted: 18-09-2019; Published online: 30-10-2019 